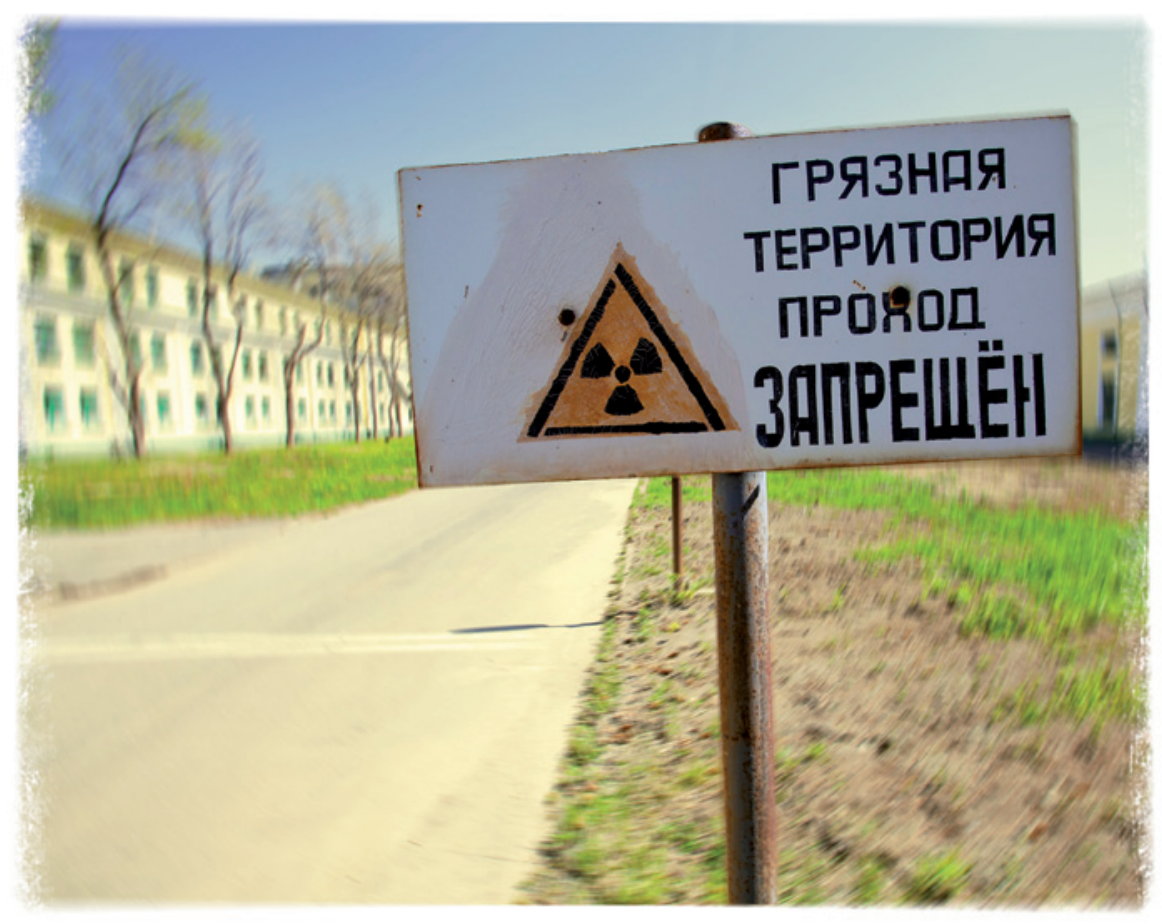

Signs near the spentfuel processing facility at Russia's Mayak Nuclear Power Plant forbid entrance to the contaminated area.

\title{
RAIDERS OF THE
}
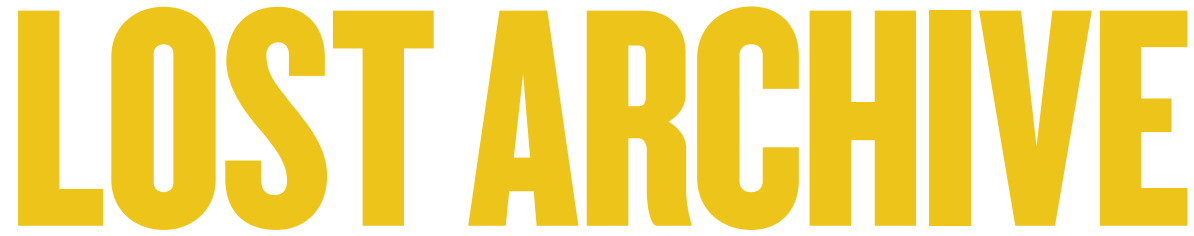

\section{Old collections of irradiated tissues could answer modern-day questions about the dangers of radiation. Now, researchers are making a concerted effort to save the stores.}

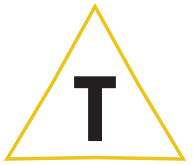

he town of Ozersk, deep in Russia's remote southern Urals, hides the relics of a massive secret experiment. From the early 1950 s to the end of the cold war, nearly 250,000 animals were systematically irradiated. Some were blasted with $\alpha-, \beta$ or $\gamma$-radiation. Others were fed radioactive particles. Some of the doses were high enough to kill the animals outright; others were so low that they seemed harmless. After the animals - mice, rats, dogs, pigs and a few monkeys - died, scientists dissected out their tissues to see what damage the radioactivity had wrought. They fixed thin slices of lung, heart, liver, brain and other organs in paraffin blocks, to be sliced and examined under the microscope. Some organs, they pickled in jars of formalin.

Fearful of a nuclear attack by the United States, the Soviet Union wanted to understand how radiation damages tissues and causes diseases such as cancer. Concerns about home-grown accidents, such as the 1957 disaster at the Mayak nuclear plant close to Ozersk, were another motivation. Throughout their experiments, the scientists carefully preserved the tissues and meticulously recorded their findings. Similar archives of irradiated tissue were built up in the United States, Europe and Japan, where nearly half a billion animals were sacrificed to the cause. But when the cold war came to an end, the collections fell into disrepair.

Now, these archives have become important to a new generation of radiobiologists, who want to explore the effects of the extremely low doses of radiation - below 100 millisieverts - that people receive during medical procedures such as computed-tomography diagnostic scans, and by living close to the damaged Fukushima nuclear reactors in Japan.

The old collections provide a resource that could not be recreated today. Most of the experiments were done under precise conditions, at a wide range of radiation doses and usually for the lifetime of the animals. "We will never be able to repeat the scale of those animal experiments, for both funding and ethical reasons," says Gayle Woloschak, a radiation biologist at Northwestern University in Chicago, Illinois. "But maybe we can reuse the legacy tissue." Over the past few years, researchers around the world have organized an effort to identify and save tissue archives from all the major animal irradiation experiments, and they have won support from a diverse range of funding agencies, including the European Commission, the US National Cancer Institute and the US Department of Energy.

But the challenges are still great. Researchers have to show that the age of the samples, and the preservation techniques used on them, have not affected the DNA, RNA and proteins the samples contain. They have to piece together such molecular data to reveal whether cell circuitry is disrupted at low radiation doses. Their early tests are indicating that some of the samples will be usable, making them regret how much of such painstakingly collected material around the world has already been lost.

\section{RADIATION RESERVOIRS}

When the ageing survivors of the Hiroshima and Nagasaki nuclear bombs and the contaminated Mayak workers started to develop cardiovascular disease at above-normal rates ${ }^{1,2}$, it became clear that radiation does more than just cause cancer. What is not known is whether or how very low doses of radiation might increase the risk of these and other diseases. Biologists have generally assumed that the damage will be proportional to the dose, but in vitro studies have shown that cells can 
repair modest DNA damage caused by radiation - and that low-dose radiation might even protect the cell against future exposure.

"Maybe there is a threshold dose below which radiation is not harmful," says Wolfgang Weiss, head of radiation protection and health at Germany's Federal Office for Radiation Protection in Munich. Epidemiological studies on people exposed to radiation through their jobs, nuclear accidents or medical procedures haven't shed much light on the matter. Some of the studies contained too few people to detect what could be a tiny increased incidence in disease; in others, it is unclear what dose the individuals received. So although radiation protection agencies typically restrict occupational exposure (for the nuclear industry, for example) to an average of $20 \mathrm{mSv}$ per year, scientists don't have hard data on which to base high-stake conclusions about what level of radiation, if any, is really safe. The old animal tissues could hold some of the answers.

In February 2007, the quest to find such tissues took Soile Tapio on a mission from one of Germany's former nuclear research centres, the Helmholtz Centre Munich, to a dark, frigid Ozersk. Tapio was taking part in a programme called the Promotion of the European Radiobiology Archives (ERA-PRO), part of an effort dating back to 1996 to digitize the data from radiation experiments done in Europe. In 2006, the director of the animal irradiation programme at the Southern Urals Biophysics Institute (SUBI) in Ozersk alerted Tapio to the enormous scope of the studies there. "At the time we didn't know much more about SUBI than its name," Tapio says. She certainly hadn't known quite what to expect when she set off there with her small ERA-PRO delegation.

\section{OFF-LIMITS}

It had already taken a few months to get approval from Russia to visit the closed town of Ozersk. After a long flight, a three-hour drive and a lengthy security clearance, a small group of ageing scientists led the delegation to an abandoned house with a gaping roof and broken windows. Glass slides and laboratory notebooks lay strewn on the floors of some offices. But other, heated rooms held wooden cases stacked with slides and wax blocks in plastic bags. In its heyday, the programme had more than 100 staff; but when it was abruptly shut down in the wake of the cold war, just four or five people were left to look after the material it had produced. The visitors were impressed to find that these scientists could link all the samples, from 23,000 animals, to detailed protocols of individual experiments. "The scientists were so happy that at last someone was taking notice of the collection," says Tapio. "They told me many times that they wanted to bring it into order before they died."

Meanwhile, another tissue rescue operation was taking place in the United States. In the mid-1990s, Woloschak had worked on samples from 7,000 beagles and 50,000 mice that had been irradiated in experiments at the Argonne Research Laboratory in Illinois between 1969 and 1992. But after she moved to Northwestern, she was dismayed to hear that the samples were being thrown out and secured permission from the Department of Energy to store them at Northwestern.

"When the community found out I had all the Argonne tissues they began to ask if I could save their tissues, too," Woloschak says. Northwestern University is now the official home for material from all US animal irradiation studies, and Woloschak estimates that she has so far received 20,000 samples. But she has also discovered that many samples have already been destroyed, including those from vast mouse studies done at Oak Ridge National Laboratory in Tennessee and some large-scale dog studies conducted at the University of California, Davis. Woloschak says that she "felt frustrated and angry that the government had invested so many millions of dollars - and immense human effort into studies that were just going to be trashed because of concerns about space". Tissue collections have also been destroyed elsewhere, including from experiments done at Hiroshima University in Japan, the Italian National Agency for New Technologies, Energy and Sustainable Economic Development's research centre in Casaccia and the UK Medical Research Council's complex in Harwell.

Scientists know that laying their hands on the old tissues will be just the first challenge: they then have to work out whether the biomolecules in the materials can still be detected and measured. They want to identify and analyse the molecular pathways hit by lowdose radiation to see how cells in different tissues adjust - or fail to adjust — to the stress, and how that might set them on the path to disease. They also want to find patterns of biological molecules that might help to determine how much radiation a person received or whether he or she is particularly susceptible to radiation-induced illness.
Woloschak's 1990s work on the old Argonne lab mouse samples provides some hope. She found, for example, that by using a technique called the polymerase chain reaction to amplify genes, she could detect mutations or rearrangements in cancer-specific genes in irradiated tissue that had turned cancerous ${ }^{3}$. Tapio, meanwhile, has adapted standard proteomics techniques so that they can be applied to some of the old tissues, and several groups are studying whether micro-RNAs - which help to control gene expression and are relatively stable - are present in the samples.

Scientists are now poised to apply such work systematically to the legacy tissues. Tapio, for example, is about to start work on paraffinembedded heart tissue from irradiated mice from the old Russian and US studies. She wants to identify any signs of damage that might explain the elevated incidence of cardiovascular disease in nuclear-bomb survivors. "The scientists who did those studies were only looking for cancer, but we can now look at other diseases we know are relevant," she says.

No one is expecting the answers to be quick or simple. The studies could identify many molecular responses that have little to do with disease. "The cell's stress response to any dose of radiation - below that which just fries it - is a complex web of activities, probably affecting many different molecular pathways," says Tapio. And radiobiologists expect that the threshold 'safe' dose will vary between tissues and between individuals.

But at the very least, the tissues in Ozersk have been brought to order, as their guardians hoped. They will soon move into a state-of-the-art storage building being built in the SUBI campus, along with human tissues from radiation-exposed Mayak workers. The animal tissues, researchers hope, will find a new experimental life - this time on an international stage.

\section{Alison Abbott is Nature's senior European correspondent.}

\section{For a podcast on irradiation work, see: go.nature.com/jeagkg}

NATURE.CON
1. Little, M. P. et al. Radiat. Environ. Biophys. 49, 139-153 (2010).

2. Azizova, T. V. et al. Radiat. Environ. Biophys. 50, 539-552 (2011).

3. Haley, B. et al. Health Phys. 100, 613-621 (2011). 